\title{
Male circumcision performed with 8-figure non-absorbable suture technique
}

\author{
Ren Chong Xi, MD;* Yin Rui Sheng, MD; ; Wang Hong Chen, MD;* Li Sheng, MD; Ji Jing Gang, MD;* Zhou Tong, \\ MD; Zhang Shan, MD; ${ }^{*}$ Yang Feng Shuo, MD,* Zhang Zhi Gang, MD; ${ }^{*}$ Yu Guo Sheng, MD; Xu Jun Ling, MD;

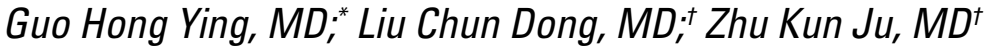

\begin{abstract}
*Department of Urology, Cangzhou Clinical College of Integrated Traditional Chinese and Western Medicine of Hebei Medical University, Cangzhou, China; 'Department of Educational Research, Cangzhou Clinical College of Integrated Traditional Chinese and Western Medicine of Hebei Medical University, Cangzhou, China
\end{abstract}

Cite as: Can Urol Assoc J 2014;8(3-4):e142-7. http://dx.doi.org/10.5489/cuaj.1521 Published online March 11, 2014.

\section{Abstract}

Introduction: We analyze the outcome of circumcisions performed with 8-figure non-absorbable suture (8FNS) and assess the feasibility of using the technique in male circumcision.

Methods: We randomly divided 317 patients who would undergo circumcision between February 2009 and January 2012 into 2 groups. Each group was subdivided into children (age range: 7 to 15 years) and adult (range: 16 to 85 years). In the experiment group ( $n=166$ ), we used 8FNS and in control group $(n=151)$, commonly absorbable suture (CAS) were used for the circumcised wound closure. The results of 2 groups were compared. We also performed a cost analysis and a mean 6-month follow-up (range: $1-12)$. Chi-square and Student's t-test were used in statistical analysis. Differences were considered significant $(p<0.05)$.

Results: No patients were required to remove their sutures postoperatively. Among them, the sutures of the 8FNS for circumcision fell off spontaneously within 9 days $(6.2 \pm 1.57)$. There was no statistically significant difference between the 2 groups in surgical duration $(16.2 \pm 1.73$ vs. $15.8 \pm 2.01)$ and follow-up time $(6.4 \pm 3.82$ vs. $6.2 \pm 2.39$ ). The overall complication rate of the 2 groups was $6.63 \%$ and $10.53 \%(p=0.15)$, respectively. In addition, the complication rate among the adults was significantly lower in the 8FNS group compared to children $(2.53 \%$ vs. $10.34 \%, p=0.04)$. Also, the average cost (in US dollars) of 8FNS for circumcision was $\$ 20.7 \pm \$ 3.83$ less than $\$ 35.8 \pm \$ 5.02$ of CAS, which is a very significant difference $(p<0.0001)$.

Conclusions: 8FNS for circumcision is feasible, easy, safe and costeffective, especially for adult males.

\section{Introduction}

Male circumcision is the oldest known human surgical procedure; its practice is increasing. ${ }^{1}$ It is estimated that 1 out of 3 males worldwide is circumcised. ${ }^{2}$ Circumcision has been described in ancient Egyptian papyri dating 4000 BC for hygienic and religious reasons. Now it is performed as a routine procedure by Jews and Muslims. Evidence suggests that male circumcision affords very strong protection against penile cancer, reduces HIV infection risk, protects against sexually transmitted diseases and urinary tract infection, and improves genital hygiene. ${ }^{3,4}$ While a $30 \%$ male circumcision prevalence exists worldwide, ${ }^{5}$ only $5 \%$ or less of the Chinese males have undergone circumcision. ${ }^{6}$ Most circumcisions currently performed in China are for phimosis or balanitis and patients are not looking for the denuded glans appearance of a ritual circumcision. In fact, more people have realized the efficacy of circumcision in preventing the acquisition and transmission of sexually transmitted infections., Circumcision is common, yet there is no standard regarding operative techniques or materials. The basic principle in circumcision is to ensure that safety and morbidity should be kept to a minimum, no matter what technique is employed. In addition, surgery cost should also be considered.

A great variety of materials, devices and techniques are used for circumcision and there is a need to identify which provide the best outcomes for males. Currently, device methods have lower complication rates when compared to common absorbable sutures (CAS). However, devices for circumcision may not be readily available or may be expensive. In fact, the basic principle in circumcision is to ensure that safety and morbidity should be kept to a minimum, no matter what technique is employed. Cost must also be considered. Although present techniques produce good long-term results, there is a continuing need to improve the safety and efficacy of circumcision. The introduction of a newly modified circumcision method has made it possible to improve the results of the procedure. This method is called the 8-figure non-absorbable suture (8FNS) technique.

In this study, we analyze the results of the 8FNS technique and the complication rates. We also performed a cost analysis. 


\section{Methods}

\section{Clinical data}

Between February 2009 and January 2012, a total of 358 male patients were circumcised for phimosis or excess foreskin at Cangzhou Clinical College of Integrated Traditional Chinese and Western Medicine of Hebei Medical University. Of the 358 patients, 41 refused participation. To be included in the study, patients had to be male, $\geq 7$ years old (children with intact prepuce requiring circumcision for religious or cultural reasons), and have medical indications for circumcision, such as phimosis, paraphimosis and balanoprothitis. In total, 317 patients were included. These patients would undergo circumcision and were randomly divided into 2 groups (Fig. 1). The experiment group (8FNS) included 166 patients and the control group had 151 patients. Each group was further subdivided into children (age range: 7-15) and adult (age range: 16-85). Several perioperative data, including age, indications, operation time, complications, postoperative pain and surgery cost, were analyzed. We compared the 8FNS and the CAS techniques. All participants were provided with information about the benefits and risks associated with the procedure. All adult participants and parents of children were required to sign a consent form before being enrolled in the study. Approval for this study was obtained from the Ethics and Human Subjects Committee of Cangzhou Clinical College of Integrated Traditional Chinese and Western Medicine of Hebei Medical University.

\section{Examination of foreskin}

The area under and around the foreskin was examined for inflammation and warts and assessed to see whether it could be pulled over and stretched. Surgical contraindications were defined as the presence of acute inflammation, uncontrolled diabetes mellitus and concealed penile phimosis. Males born with penile anomalies (hypospadias, epispadias or megalourethra) and children with ammonia dermatitis were excluded from the study.

\section{Disinfection and anesthesia}

Disinfection was accomplished by applying disinfectant iodophor solution around the penis and involved tissues and by covering the operative site with a surgical drape. The dorsal penile nerve was blocked by a local anesthetic solution of $1 \%$ lidocaine using a 24 -gauge needle in adults. Injection points were located at the 2 and 10 o'clock positions of the root of the penis where the dorsal nerves of penis pass through. ${ }^{9,10}$ The recommended anesthetic dose varied from $3 \mathrm{~mL}$ to $5 \mathrm{~mL}$. Before surgery, all children were under general anesthesia, while adults had local anesthesia with sedation.

\section{FNS for circumcision}

8FNS initiated after the redundant prepuce was circumcised by conventional techniques and wound bleeding was effectively controlled. The "Mersilk" suture (Ethicon) (non-absorbable suture, 1/0 for adults, 4/0 for children) was selected and used in the modified circumcision. Holding forceps or the mosquito clamp, we sutured the foreskin inner and outer lamina close to the wound edge and ensured that the stitching thickness was no more than $0.1 \mathrm{~cm}$. Two sutures intersected the outside of the wound (just decussation without the knot). The lower half of the figure 8 was done at this time (Fig. 2, part A). The surgical assistant then place the prepared sterile Vaseline gauze (diameter $0.3-0.5 \mathrm{~cm}$ ) on the suture intersection point (Fig. 2, part B). The gauze was ligatured on the outside of the wound outside by moderately tightening the sutures and the knots (Fig. 2, part C). At this point, the complete figure 8 was done (Fig. 2, part D). After meticulous hemostasis, the surgeon sutured 4 points respectively at the dorsal, ventral, left and right side of the edge of the wound with a "Mersilk" suture. When suturing at the ventral side, the surgeon should try to match the frenulum preputii with the raphe penis. The rest of the wound edge was sutured at distances spaced between 0.5 and $1.5 \mathrm{~cm}$. CAS for circumcision was omitted. Postoperative pain (Visual analogue scale [VAS] $>4$ ) was measured. We also performed a cost analysis (according to local charging standards) and a mean 6-month follow-up (range: 1 to 12 months). Chi-square and Student's t-test were used in the statistical analysis. Significance was determined as $p<0.05$.

\section{Results}

No patients were required to remove their sutures postoperatively. Among them, the sutures of the 8FNS for circumcision fell off spontaneously within 9 days $(6.2 \pm 1.57)$. There was no statistically significant difference between the 2 groups in surgical duration $(16.2 \pm 1.73$ vs. $15.8 \pm 2.01)$ and follow-up time $(6.4 \pm 3.82$ vs. $6.2 \pm 2.39)$. The overall complication rate of the 2 groups was $6.63 \%$ and $10.53 \%(p=0.15)$, respectively. In addition, the complication rate of the adults was significantly lower in the 8FNS group compared to children $(2.53 \%$ vs. $10.34 \%, p=0.04)$. Also, the average cost of the 8FNS for circumcision was $\$ 20.7 \pm \$ 3.83$ less than $\$ 35.8 \pm \$ 5.02$ of the CAS method - a very significant difference $(p<0.0001)$. We tallied the outcomes and characteristics of 8 FNS for circumcision (Table 1 ) and the postoperative complications between the 2 groups (Table 2). 


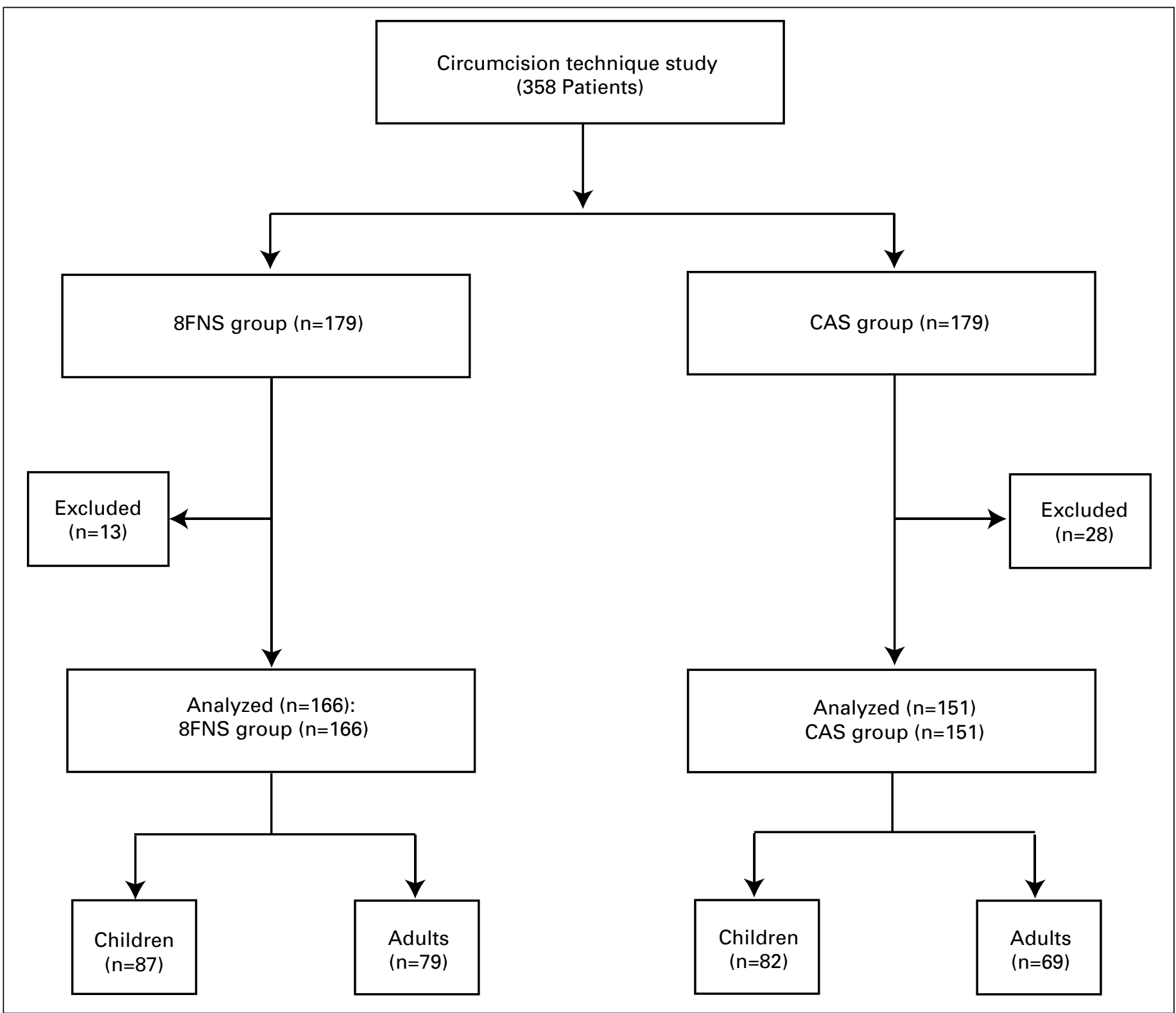

Fig. 1. Grouping randomly for subjects. FNS: figure non-absorbable suture; CAS: commonly absorbable suture.

\section{Discussion}

In our study, we found that $8 \mathrm{FNS}$ for circumcision is superior to CAS, though our 2 patient groups similarly did not require an immediate removal of their sutures postoperatively. The groups also had similar surgical duration, follow-up time and overall complication rate. Significant differences were found in the average cost of the circumcision between the 8FNS and the CAS methods $(\$ 20.7 \pm \$ 3.83$ vs. $\$ 35.8 \pm \$ 5.02$, respectively). Moreover, in the $8 \mathrm{FNS}$ group, the complication rate of the adults was significantly lower compared to children $(2.53 \%$ vs. $10.34 \%, p=0.04)$. Our results demonstrate that $8 \mathrm{FNS}$ for circumcision is easy, safe, cost-effective and particularly suitable for adult males. None of the patients needed their sutures to be removed postoperatively; therefore, we were able to assess the spontaneous fall off of the sutures.

To perform an 8FNS suture, a small-sized tissue (0.05$0.1 \mathrm{~cm}$ ) sutured from the wound is an important prerequisite. The non-absorbable suture itself acts as a scalpel, which appears to be continuous cutting, in the sutured tissue. Moreover, a certain degree of tension is maintained by ligating the Vaseline gauze moderately after the 8FNS is done. Both the suture itself and the Vaseline gauze attached to wound edge can exert moderate and persistent force on the ligated tissues. This ensures that the tissues will be cut 


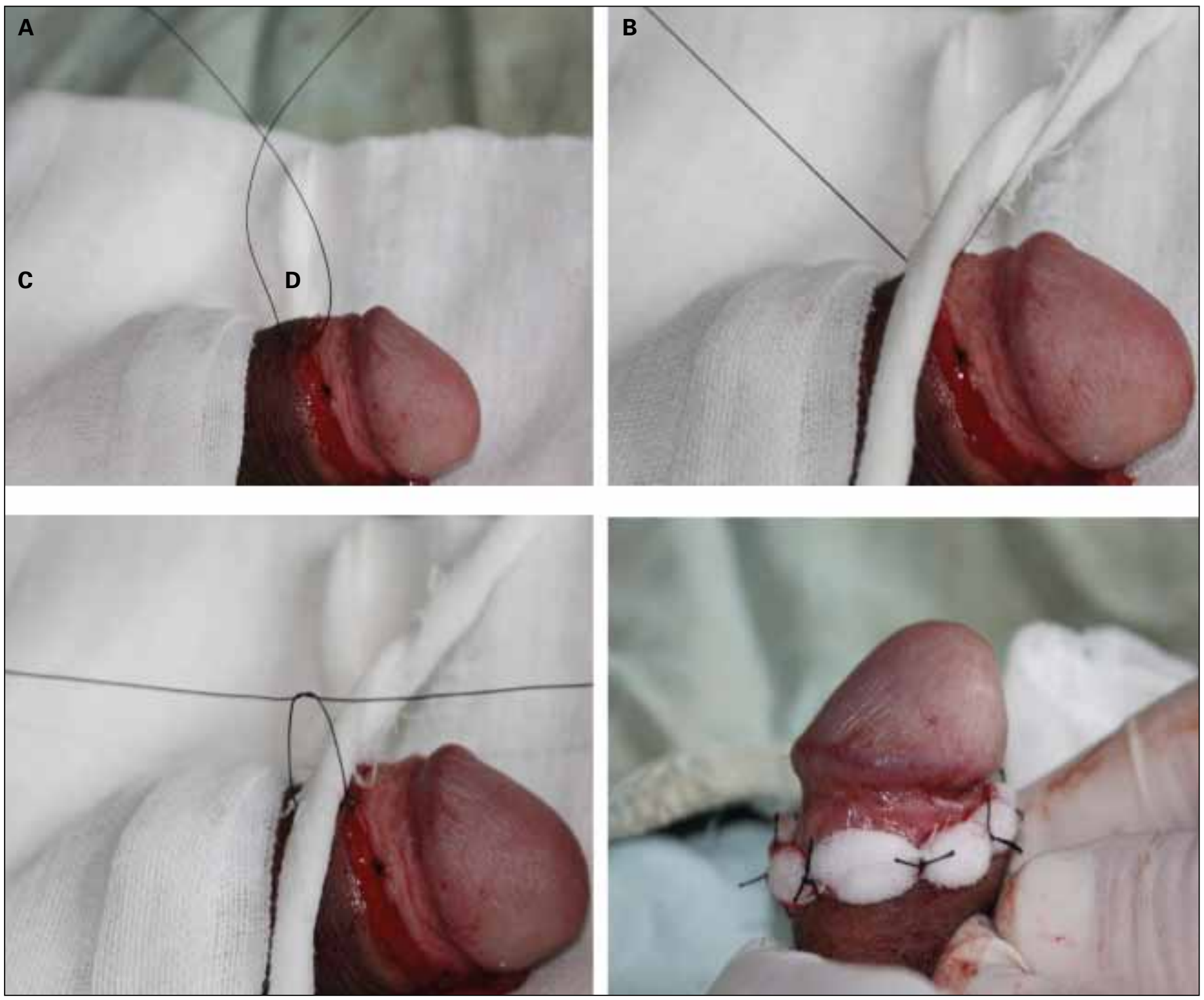

Fig. 2. A: Holding forceps or mosquito clamp, the foreskin inner and outer lamina of incision were interrupted sutures closely to wound edge and the stitching thickness was no more than $0.1 \mathrm{~cm}$. Two sutures taken were intersected the wound outside (Just decussation without knot). The lower half of the figure 8 had been formed at this time. B: Then the assistant put the prepared sterile vaseline gauze (diameter $0.3-0.5 \mathrm{~cm}$ ) on the suture intersection point. C: The vaseline gauze was ligatured the wound outside by moderately tightening sutures and the knots attached to the Vaseline gauze. D: A complete figure 8 has been formed.

off gradually, and that the wound edge tissues of both inner and outer foreskin layers will not split. There are few in vivo studies evaluating the tissue reaction to suture materials that mainly depend on how the suture polymer interacts with the tissues. ${ }^{11}$ Non-absorbable sutures include silk (now infrequently used) and several synthetic materials designed for elasticity, easy handling, good knot security and minimal tissue irritation.

Non-absorbable sutures are also inexpensive. Choosing the right suture is an important factor in better wound closures. ${ }^{12}$ The "Mensilk" suture, as a non-absorbable synthetic polyester which we usually use in phimosis or excess fore-
Table 1. The outcomes and characteristics of two groups

\begin{tabular}{lcccc}
\hline $\begin{array}{l}\text { Outcomes and } \\
\text { characteristics }\end{array}$ & $\begin{array}{c}\text { 8-FNS } \\
\text { (experiment) } \\
\mathbf{n = 1 6 6}\end{array}$ & $\begin{array}{c}\text { CAS } \\
\text { (control) } \\
\mathbf{N}=\mathbf{1 5 1}\end{array}$ & $\begin{array}{c}\text { Student's } \\
\text { t-test }\end{array}$ & $\boldsymbol{p}$ value \\
\hline $\begin{array}{l}\text { Surgical } \\
\text { duration (hours) }\end{array}$ & $16.2 \pm 1.73$ & $15.8 \pm 2.01$ & 1.90 & 0.058 \\
$\begin{array}{l}\text { Follow-up } \\
\text { (months) }\end{array}$ & $6.4 \pm 3.82$ & $6.2 \pm 2.39$ & 0.55 & 0.581 \\
$\begin{array}{l}\text { Average cost } \\
\text { (USD) }\end{array}$ & $20.7 \pm 3.83$ & $35.8 \pm 5.02$ & 30.26 & $<0.0001$ \\
$\begin{array}{l}\text { Fall-off duration } \\
\text { (days) }\end{array}$ & $6.2 \pm 1.57$ & & & \\
\hline FNS: figure non-absorbable suture; CAS: commonly absorbable suture; USD: US dollars.
\end{tabular}


Xi et al.

\begin{tabular}{|c|c|c|c|c|c|c|c|c|}
\hline \multirow[t]{2}{*}{ Wound complications } & \multicolumn{3}{|c|}{ 8-FNS (experiment) } & \multicolumn{3}{|c|}{ CAS (control) } & \multirow[b]{2}{*}{$\chi^{2}$} & \multirow[b]{2}{*}{$p$ value } \\
\hline & $\begin{array}{c}\text { Children } \\
n=87(\%)\end{array}$ & $\begin{array}{c}\text { Adult } \\
\mathrm{n}=79(\%)\end{array}$ & $\boldsymbol{p}$ value & $\begin{array}{c}\text { Children } \\
n=82(\%)\end{array}$ & $\begin{array}{c}\text { Adult } \\
\mathrm{n}=69(\%)\end{array}$ & $\boldsymbol{p}$ value & & \\
\hline Bleeding & $2(2.29)$ & $0(0.00)$ & & $1(1.22)$ & $1(1.45)$ & & & \\
\hline Infection & $1(1.15)$ & $0(0.00)$ & & $1(1.22)$ & $1(1.45)$ & & & \\
\hline Edema & $2(2.29)$ & $1(1.27)$ & & $3(3.66)$ & $1(1.45)$ & & & \\
\hline Pain & $2(2.29)$ & $1(1.27)$ & & $1(1.22)$ & $2(2.90)$ & & & \\
\hline Hematoma & $1(1.15)$ & $0(0.00)$ & & $2(2.44)$ & $1(1.45)$ & & & \\
\hline Dehiscence & $1(1.15)$ & $0(0.00)$ & & $0(0.00)$ & $0(0.00)$ & & & \\
\hline Scleroma & $0(0.00)$ & $0(0.00)$ & & $1(1.22)$ & $2(2.90)$ & & & \\
\hline Total & $9(10.34)$ & $2(2.53)$ & 0.04 & $9(10.96)$ & $8(11.60)$ & 0.90 & 2.11 & 0.15 \\
\hline
\end{tabular}

skin surgery, may cause minimal tissue reaction, but there is no hydrolysis or hypotonia in the short term. If the tissue is stitched too tightly, the sutures may not fall off. In contrast, if the sutures are too loose, then this may lead to wound dehiscence because the stitches may fall off prematurely. The recommended suturing tissue width varies from 0.05 to $0.1 \mathrm{~cm}$. Results of the current study show that the overall complication rate is reduced to $6.63 \%$ when circumcision is performed with the 8FNS technique. Furthermore, we did not encounter any severe adverse events, such as dehiscence, related to use of this method in adults. Generally, the 2 most common complications of circumcision are bleeding and wound infection..$^{13}$ One of the most common complication of circumcision is bleeding, with rates as high as 35\%. ${ }^{14}$ Using the Plastibell device (Hollister Inc., Seattle, WA) for circumcision, Lazarus and colleagues found that bleeding was the most common complication (7/16 cases or $44 \%)$ among cases presenting at the hospital after circumcisions done outside the hospital. Incision bleeding was seen in 2 children, only accounting for $1.20 \%$ of the total cases in our study. Moreover, we had no cases of bleeding. We observed only $0.60 \%$ cases of wound infection. The infection rate was lower than the $8.2 \%$ associated with the conventional procedure circumcision as reported by Rizvi and colleagues. ${ }^{16}$ In a study that used the Korean style of circumsion, Ge and Liu reported complications in $50 \%$ of adults, with edema in the rim of the foreskin. ${ }^{17}$ Comparatively, in our study, the incidence of edema was only $1.80 \%$. There was reported pain from nocturnal erections in $78 \%$ of the patients from the Ge and Liu study, although the pain was lessened by the oral use of diethylstilbestrol before bedtime. The rate of pain in our study was only $1.80 \%$. As to $8 \mathrm{FNS}$ for circumcision, the greatest advantage is cost in that suture material is less expensive. This should not be downplayed, especially in low- and middle-income countries where circumcision is not practiced routinely.

This study has several limitations. Costing data were obtained from our hospital in China and costs may be different in other regions in the country or in other nations.

\section{Conclusion}

Based on our findings, the 8FNS method is easy, safe and cost-effective, especially for adult males.

Acknowledgements: We would like to thank the Department of Educational Research and Operating Theatre at Cangzhou Clinical College of Integrated Traditional Chinese and Western Medicine at Hebei Medical University. We would like to thank the Department of Urology at Cangzhou First People's Hospital.

Competing interests: Dr. Xi, Dr. YR Sheng, Dr. Chen, Dr. Sheng, Dr. J. Gang, Dr. Tong, Dr. Shan, Dr. Shuo, Dr. Z Gang, Dr. YG Sheng, Dr. Ling, Dr. Ying, Dr. Dong and Dr. Ju all declare no competing financial or personal interests.

This paper has been peer-reviewed.

\section{References}

1. Alanis MC, Lucidi RS. Neonatal circumcision: A review of the world's oldest and most controversial operation. Obst Gyneco Surv 2004;59:379-95. http://dx.doi.org/10.1097/00006254-200405000-00026

2. Joint United Nations Programme on HIV/AIDS (UNAIDS) WHO/UNAIDS. Neonatal and child male circumcision: A global review; 2010. http://www.who.int/hiv/pub/malecircumcision/neonatal_child_MC_ UNAIDS.pdf?ua=l (Accessed February 24, 2014).

3. Ben KL, Xu JC, Lu L, et al. Promoting male circumcision in China for preventing HIV infection and improving reproductive health. Zhonghua Nan Ke Xue 2008;14:291-7.

4. Male circumcision for HIV prevention: Research implications for policy and programming. WHO/UNAIDS technical consultation, 6-8 March 2007. Conclusions and recommendations (excerpts). Reprod Health Matters 2007:15:11-4. http://dx.doi.org/10.1016/S0968-8080(07)29307-3

5. WHO/UNAIDS. Male circumcision: Global trends and determinants of prevalence, safety and acceptability. World Health Organization; 2008.

6. Ben KL, XU JC, Lu L, et al. Male circumcision is an effective "surgical vaccine" for HIV prevention and reproductive health. Zhonghua Nan Ke Xue 2009;15:395-402.

7. Perera $\mathrm{CL}$, Bridgewater $\mathrm{FH}$, Thavaneswaran $\mathrm{P}$, et al. Safety and efficacy of nontherapeutic male circumcision: A systematic review. Ann Fam Med 2010;8:64-72. http://dx.doi.org/10.1370/afm.1073

8. Wang ML, Macklin EA, Tracy E, et al. Updated parental viewpoints on male neonatal circumcision in the United States. Clin Pediatr (Phila) 2010;49:130-6. http://dx.doi.org/10.1177/0009922809346569

9. Xiao YH, Liu ZL, Peng SL, et al. Anatomic evidence of dorsal penile nerve block for circumcision and its clinical applications. J Chin PLA Postgrad Med Sch (Chin) 2007;28:177-8.

10. Zhang HF, Zhang CY, Li XH, et al. Dorsal penile nerves and primary premature ejaculation. Chin Med J 2009; 122:3017-9 
11. Andrade MG, Weissman R, Reis SR. Tissue reaction and surface morphology of absorbable sutures after in vivo exposure. J Mater Sci Mater Med 2006;17:949-61. http://dx.doi.org/10.1007/s10856006-0185-8

12. Moy RL, Lee A, Zalka A. Commonly used suture materials in skin surgery. Am Fam Phys 1991;44:2123-8.

13. Weiss $\mathrm{HA}$, Larke $\mathrm{N}$, Halperin $\mathrm{D}$, et al. Complications of circumcision in male neonates, infants and children: A systematic review. BMC Urol 2010;16:10-2.

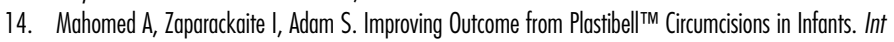
Braz I Urol 2009;35:310-4.

15. Lazarus J, Alexander A, Rode H. Circumcision complications associated with the Plastibell device. S Afr Med J 2007:97:192-3.
16. Rizvi SA, Naqui SA, Hussain M, et al. Religious circumcision: A Muslim view. Br J Urol 1999;83(Suppl 1):13-6. http://dx.doi.org/10.1046/i.1464-410x.1999.0830s1013.x

17. Ge CG, Liu DL. Clinical observation of adult circumcision with removal ring device. Chin J Mod Med 2005; 15:3028-30

Correspondence: Dr. Ren Chong Xi, Department of Urology, Cangzhou Clinical College of Integrated Traditional Chinese and Western Medicine of Hebei Medical University, Cangzhou 061000, China; qdrcx2008@aliyun.com 